\section{$\left[{ }^{11} \mathrm{C}\right] N N C$ 12-0722 or $\left[{ }^{18} \mathrm{~F}\right] \mathrm{GBR} 13119$ : Just What Is "Better"?}

Dear Sir,

In their recent paper Muller et al. [1] have presented a very preliminary evaluation of a potential new PET radioligand for the dopamine transporter, $\left[{ }^{11} \mathrm{C}\right] \mathrm{NNC} 12$ 0722. This is a compound derived from the better known ligands for that site, GBR 12935 and GBR 12909. In their paper, the authors discuss previous efforts to utilize a fluorine-18 analog of these compounds, namely $\left[{ }^{18} \mathrm{~F}\right]$ GBR 13119 (which is fluoroGBR 12935, or desfluoroGBR 12909), and they state “...brain uptake was general and there was no marked accumulation of radioactivity in regions known to have a high density of dopamine transporters" (authors' own words). This statement is grossly erroneous.

We had done extensive evaluation of $\left[{ }^{18} \mathrm{~F}\right] \mathrm{GBR}$ 13119 , and the closely related compound $\left[{ }^{18} \mathrm{~F}\right] \mathrm{GBR}$ 12909 , including studies in rodents, monkeys and man. The monkey PET image published by us (and referenced by the authors) clearly shows bilateral accumulation of the radiotracer, $\left[{ }^{18} \mathrm{~F}\right] \mathrm{GBR} 13119$, in the striatum of the monkey brain [2]. That paper also presents the pharmacokinetic time course for radioactivity in striatum and cerebellum, clearly showing a differential accumulation in the DA transporter-rich striatal tissue. The striatum to cerebellum ratios in monkeys were 1.5-1.7, not that dissimilar than what had been previously reported in monkeys for $\left[{ }^{11} \mathrm{C}\right]$ nomifensine, a radioligand also successfully used for primate and human PET imaging of DA transporters. Our publications have documented the pharmacological specificity of the regional in vivo binding of this radiotracer in mammalian brain $[2,3]$. Finally, we have already reported human imaging and full pharmacokinetic modelling of $\left[{ }^{18} \mathrm{~F}\right] \mathrm{GBR} 12909$ in human brain [4].

Certainly some more recent radioligands, such as $\left[{ }^{11} \mathrm{C}\right] \mathrm{CIT}$, are better imaging agents but their quantitative value is still being studied. $\left[{ }^{11} \mathrm{C}\right] \mathrm{NNC} 12-0722$ might also be a better radioligand, but the authors need to do much work to prove this point. They have not demonstrated in any animal that the in vivo uptake and concentration of radioactivity in the striatum of an animal can be selectively blocked with known, structurally unrelated antagonists of the DA transporter. They have not demonstrated that the in vivo brain distribution cannot be altered by pharmacological treatments with ligands for other receptors or transporters. They have not demonstrated that the uptake in brain is not due to metabolites, which may or may not be binding to the DA transporter.
At least all of these things have been done for $\left[{ }^{18} \mathrm{~F}\right] \mathrm{GBR}$ 13119 and $\left[{ }^{18} \mathrm{~F}\right]$ GBR 12909 , even if they are not "optimal" imaging agents.

A full evaluation of $\left[{ }^{11} \mathrm{C}\right] \mathrm{NNC}$ 12-0722 is needed and should be pursued. The high brain uptake, and possibly more rapid kinetics, are indeed encouraging. Until these further studies are complete, $\left[{ }^{11} \mathrm{C}\right] \mathrm{NNC} 12-0722$ is just one of a long list of radioactive compounds, of several pharmacological classes, that will concentrate in the striatum.

Michael R. Kilbourn

Professor of Internal Medicine

University of Michigan, Ann Arbor, MI 48109, USA

\section{References}

1. Muller L, Halldin C, Foged C, Karlsson P, Hall H, Swahn CG, Suzdak PD, Hohlweg R, Nielsen EB, Farde L. Preparation of a potential positron emission tomographic radioligand for the dopamine transporter. Eur J Nucl Med 1994;21: $131-137$.

2. Kilbourn MR, Carey JE, Koeppe RE, Haka MS, Hutchins GD, Sherman PS, Kuhl DE. Biodistribution, dosimetry, metabolism and monkey PET studies of $\left[{ }^{18} \mathrm{~F}\right]$ GBR 13119. Imaging the dopamine uptake system in vivo. Nucl Med Biol 1989;16: $569-576$.

3. Ciliax BJ, Kilbourn MR, Haka MS, Penney JB Jr. Imaging the dopamine uptake site with ex vivo $\left[{ }^{18} \mathrm{~F}\right] \mathrm{GBR} 13119$ binding autoradiography in rat brain. J Neurochem 1990;55: 619-623.

4. Koeppe RA, Kilbourn MR, Frey KA, Penney JB, Haka MS, Kuhl DE. Imaging and kinetic modeling of [F-18]GBR 12909, a dopamine uptake inhibitor [abstract]. $J$ Nucl Med 1990;31: 720 .

\section{Reply}

Dear Sir,

We think that it is of principle importance to examine the potential of aryl 1,4-dialkylpiperazines as radioligands for PET imaging. The selectivity of the piperazines may be an advantage as compared to the cocaine congener $\beta$-CIT. The striatum to cerebellum ratio of $\left[{ }^{18} \mathrm{~F}\right] \mathrm{GBR} 13119$ binding in the monkey brain has been reported to be 1.51 [1]. Whether this striatal uptake should be regarded as marked or not is a semantic issue. It is clearly lower than that obtained for $\left[{ }^{[1} \mathrm{C}\right] \beta-\mathrm{CIT}$ [2] or $\left[{ }^{11} \mathrm{C}\right] \beta$-CFT, which at present are the most widely used ligands for PET imaging of the dopamine transporter. Despite thorough characterization in the rat brain in vivo and in vitro, the specificity of $\left[{ }^{18}\right.$ F]GBR 13119 bind- 